\title{
Burtonian line in a patient with occupational lead poisoning
}

\author{
Ali Banagozar Mohammadi ${ }^{1}$, Mohammadreza Moslemi $^{2}$, Alireza Mirghaffari ${ }^{1}$, and Morteza \\ Haramshahi $^{1}$ \\ ${ }^{1}$ Tabriz University of Medical Sciences \\ ${ }^{2}$ Tabriz University of Medical Sciences Faculty of Medicine
}

October 28, 2021

\begin{abstract}
In this article, we want to present a patient with Burtonian or lead line at the gum tooth line, a rare presentation of lead poisoning.
\end{abstract}

Title: Burtonian line in a patient with occupational lead poisoning

Authors :

Ali Banagozar Mohammadi ${ }^{\mathrm{a}}$, Mohammadreza Moslemi $^{\mathrm{b} *}$, Alireza Mirghaffari ${ }^{\mathrm{c}}$, Morteza Haramshahi $^{\mathrm{d}}$

a MD. Assistant professor of Forensic Medicine and Medical toxicology at faculty of medicine, Tabriz university of medical sciences

c MD, Postgraduate student of internal medicine, Department of internal medicine, School of medicine, Tabriz University of medical sciences

d MD, Postgraduate student of internal medicine, Department of internal medicine, School of medicine, Tabriz University of medical sciences

b * Corresponding Author: Mohammadreza Moslemi, MD, Postgraduate student of internal medicine, Department of internal medicine, School of medicine, Tabriz University of medical sciences, Golgasht Avenue, Tabriz, Iran

Orcid: https://orcid.org/0000-0002-0403-7156

Postal code: 5166614756

Email address: moslemi_mohammadreza@yahoo.com

Tel: +989112901593

Fax: 04133359680

Title: Burtonian line in a patient with occupational lead poisoning

Key clinical message:

More attention of the medical staff to this sign can lead to faster diagnosis and timely treatment of patients.

Abstract:

In this article, we want to present a patient with Burtonian or lead line at the gum tooth line, a rare presentation of lead poisoning. 
Key words: lead poisoning, Burton's line, Burtonian line, occupational poisoning, lead line

\section{Case presentation:}

A 32-year-old man who has been in contact with molten lead in a battery factory for four years presented to the emergency ward with a history of chronic abdominal pain with anorexia and constipation, which has worsened in the last three weeks. In addition to abdominal pain, physical examination revealed bluish gingival pigmentation, also known as Burtonian or lead line at the gum tooth line, which is a rare presentation of lead poisoning and may not be presented if the patient had good oral hygiene (1).

The laboratory testing revealed a lead blood level of 165 micrograms per deciliter (normal value, $<25$ micrograms per deciliter) and hypochromic microcytic anemia. Basophilic stippling was seen in the peripheral blood smear.

The patient has been admitted into our hospital's toxicology and poisoning ward and has been treated with the Succimer as a chelator therapy. Other treatments and diagnostic evaluations are being followed.

More attention of the medical staff to this symptom can lead to faster diagnosis and timely treatment of patients.

\section{Acknowledgment}

None

\section{Funding}

This research did not receive any specific grant from funding agencies in the public, commercial, or not-forprofit sectors.

\section{Conflicts of interest}

None

\section{Ethics}

This study was performed according to the principles outlined by the World Medical Association's Declaration of Helsinki on experimentation involving human subjects, as revised in 2000 and has been approved by the ethics committee of the Tabriz University of Medical Sciences.

\section{Author Contributions:}

Mohammadreza Moslemi : corresponding author and conception and design of report and final approval of the version to be submitted

Ali Banagozar : Final approval of the version to be submitted

Alireza Mirghaffari : Preparing figure and revising the article critically for important intellectual content

Morteza Haramshahi: Drafting the article or revising it critically for important intellectual content

Consent statement :

Written informed consent was obtained from the patient for to the publication of this report and clinical images.Consent has been signed and collected in accordance with the journal s patient consent policy.

Refrences:

1. Goldman RH, Hu H, Traub SJ. Lead exposure and poisoning in adults. Elmore JG, Traub SJ, Kunins, eds UpToDate. 2019.

Figure legends 
Figure: Bluish gingival pigmentation, also known as Burtonian or lead line at the gum tooth line of the patient

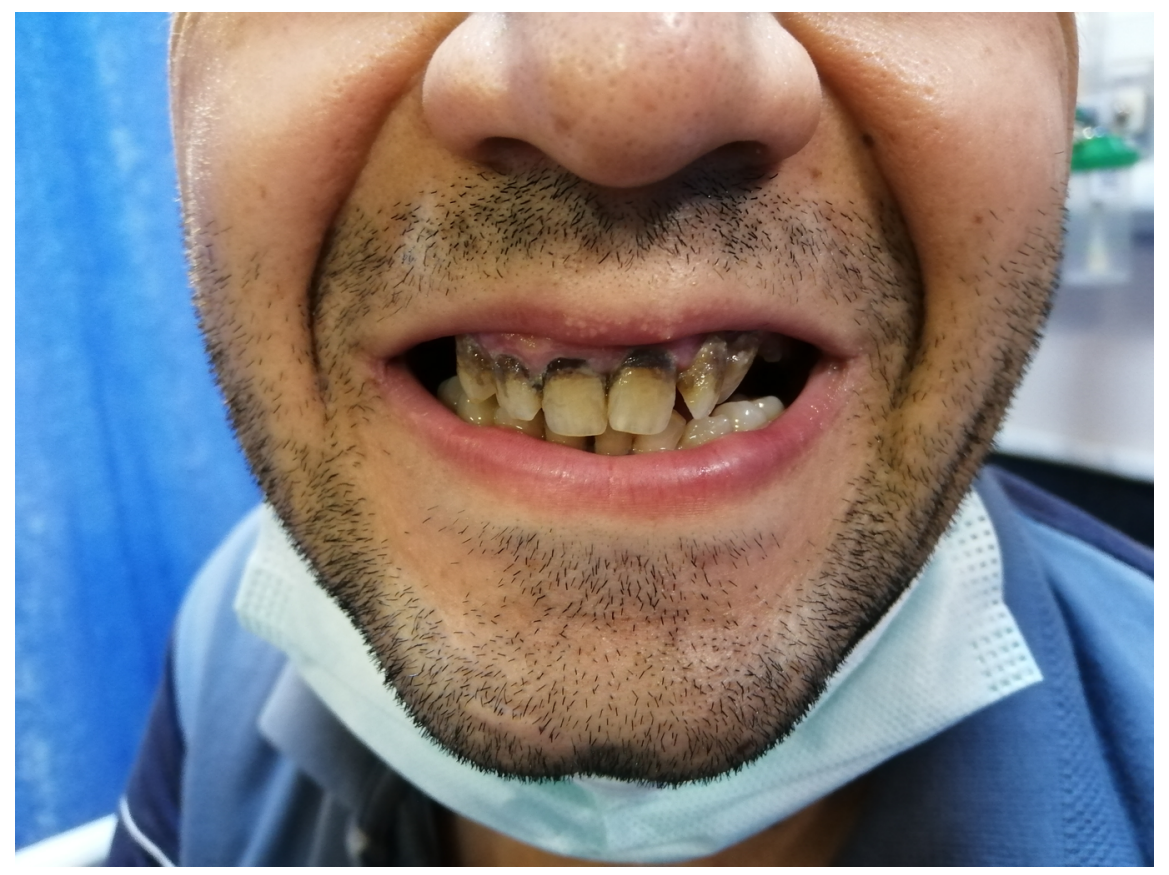

